Document downloaded from:

http://hdl.handle.net/10251/40284

This paper must be cited as:

MIGUEL RAFAEL ABARGUES LLAMAS; Ferrer, J.; ALBERTO BOUZAS BLANCO; Seco Torrecillas, A. (2013). Removal and fate of endocrine disruptors chemicals under labscalepostreatment stage. Removal assessment using light, oxygen and microalgae. Bioresource Technology. 149:142-148. doi:10.1016/j.biortech.2013.09.051.

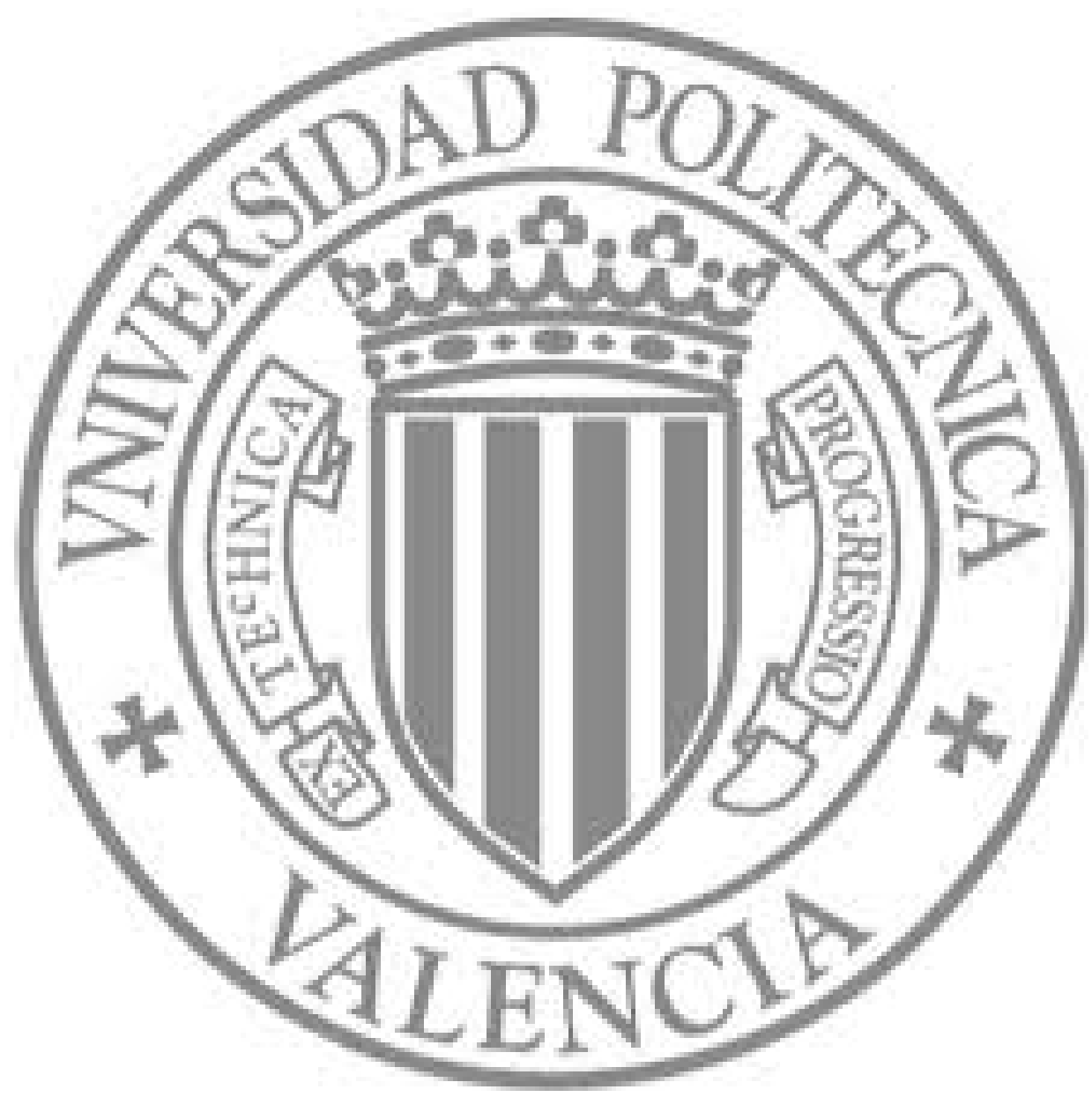

The final publication is available at

http://dx.doi.org/10.1016/j.biortech.2013.09.051

Copyright Elsevier 


\section{Removal and fate of endocrine disruptors chemicals under lab-scale postreatment stage. Removal assessment using light, oxygen and microalgae.}

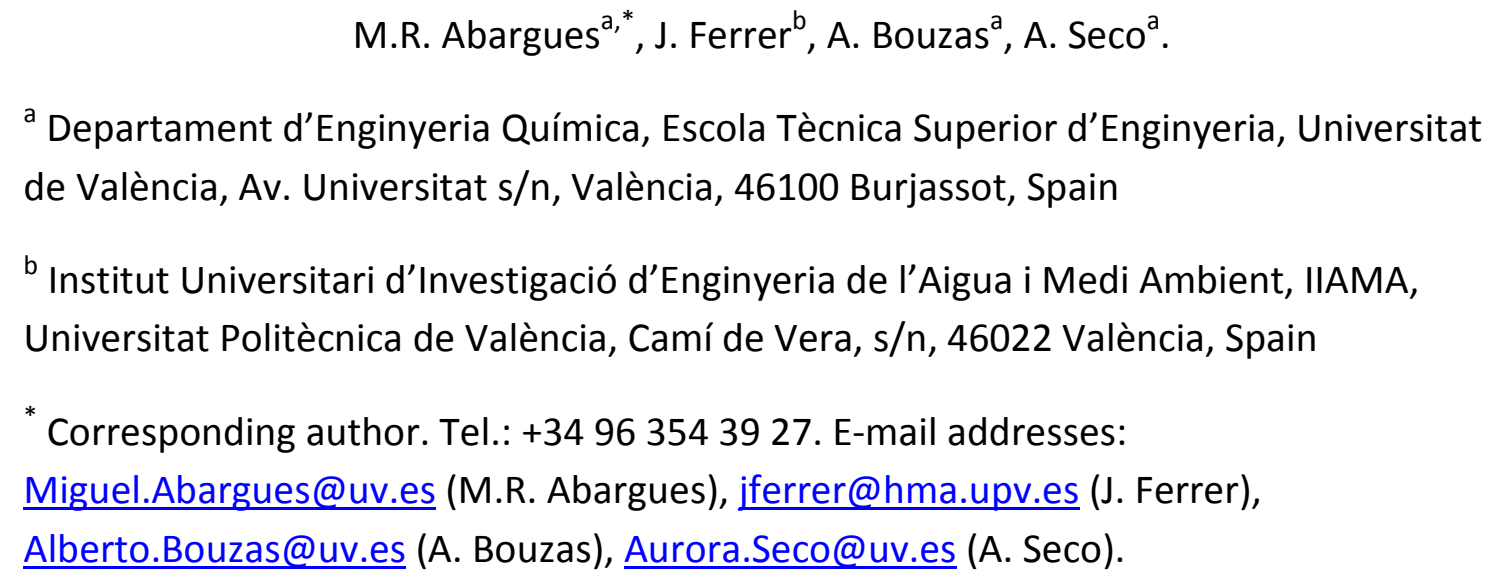

The aim of this study was to assess the effect of light, oxygen and microalgae on micropollutants removal. The studied micropollutants were 4-(1,1,3,3tetramethylbutyl)phenol (OP), technical-nonylphenol (t-NP), 4-n-nonylphenol (4-NP), Bisphenol-A (BPA). In order to study the effect of the three variables on the micropollutants removal, a factorial design was developed. The experiments were carried out in four batch reactors which treated the effluent of an anaerobic membrane bioreactor. The gas chromatography mass spectrometry was used for the measurement of the micropollutants. The results showed that light, oxygen and microalgae affected differently to the degradation ratios of each micropollutant. The results showed that under aerated conditions removal ratios higher than $91 \%$ were achieved, whereas for non-aerated conditions the removal ratios were between 50 and $80 \%$, except for 4-NP which achieved removal ratios close to $100 \%$. Besides, mass balance showed that the degradation processes were more important than the sorption processes.

\section{Keywords:}

Alkylphenol, endocrine disruptor, microalgae, wastewater treatment plant.
1. Introduction.
In recent years, several micropollutants have been detected in natural environments, mainly due to the use of manufactured products, such as surfactants, pesticides or plastic reinforcements. Some of these chemicals are able to disrupt the endocrine system. Therefore, those substances are called endocrine disruptor chemicals (EDCs). EDCs are of global concern due to their widespread occurrence, 
persistence, bioaccumulation and potential adverse effects on ecosystem functioning and human health. Nevertheless, EDCs can be removed by the action of wastewater treatment plant (WWTPs) (Clara et al., 2005; González et al., 2007).

4-(1,1,3,3-tetramethylbutyl)phenol (OP) and technical-nonylphenol (t-NP) are known as alkylphenol (APs) and are degradation metabolites of alkylphenol polyethoxylates (APEOs). The annual global production of APEOs is approximately 500,000 tons, which approximately an $80 \%$ correspond to nonylphenol polyethoxylates (NPEOS), whereas the remaining $20 \%$ correspond to octylphenol polyethoxylates (OPEOs) (Lin et al., 2010). APEOs are commonly used in the formulation of a large variety of detergents, paints, lubricants, resins, and pesticides (Sharma et al., 2009). The toxicity of APEOs increases with decreasing ethoxylates chain length (Careri et al., 2003). Due to APs are more lipophilic than APEOs, these biotransformation metabolites are more toxic than APEOs. The estrogenic activity observed appeared to be confined to para- or 4 substituted compounds (Jobling and Sumpter, 1993). Mentioned estrogenic activity became stronger with the increase in the number of the alkyl carbons, being this activity maximized with a nonyl- chain. Phenol shows weak estrogenic activity, whereas anisole was completely inactive (Tabira et al., 1999). Several reports have demonstrated that these EDCs can accumulate due to high stability and lipophilicity, and thus, EDCs can affect endocrine systems in fishes and birds. Therefore, these compounds can spread to humans via the food chain (Jobling and Sumpter, 1993; Manente et al., 2011).

4-n-nonylphenol (4-NP) is an alkylphenol, but it is not a metabolite of APEOs, and thus, its occurrence in environment is infrequent (de Weert et al., 2010). Moreover, its biodegradability is higher than OP and t-NP biodegradability due to the linear chain of 4-NP presents a secondary carbon attached to C4 position of aromatic ring which is less resistant than the quaternary carbon of t-nonylphenol under both aerobic and anaerobic conditions (Corvini et al., 2006; Abargues et al., 2012; Porter et al., 2012).

BPA is principally used in the production of epoxy resins and polycarbonate plastics as a monomer. BPA can interfere in cell division mechanism, as well as mimic the female estrogen E2 (Sharma et al., 2009; Gattullo et al., 2012). Several authors confirmed that BPA presents poor biodegradation under anaerobic conditions in both suspended and soluble fractions (Ike et al., 2006), whereas its biodegradability increases under aerobic conditions (Kang and Kondo, 2002).

The Directive 2000/60/EC, also known as Water Framework Directive (WFD), is probably the most significant international legislation in the field of water from many years and its aim is to improve, protect and prevent further deterioration of water 
quality across Europe (Allan et al., 2006). WFD includes and protects different kinds of water in Europe (surface water, groundwater, transitional and coastal) with the aim to achieve and ensure a good quality for all of them. WFD includes as priority substances the OP and 4-NP studied. Furthermore, Directive 2008/105/EC lays down environmental quality standards (EQS) for priority substances and certain other pollutants as provided for in WFD. The Directive 2008/105/EC establishes the extent permitted of OP and 4-NP in inland and other surface waters. So, attention must be paid on the fate of these substances in order to fulfill the WFD requirements. Furthermore, the proposal for a Directive 2011/0429 (COD) added t-NP to the list of priority substances, laying down EQS for these substances.

The removal of EDCs in WWTPs can be carried out by aerobic and anaerobic process. Several works showed that the concentrations of OP and t-NP were increased during anaerobic treatment, whereas it was observed an effective removal after aerobic activated sludge treatment (Janex-Habibi et al., 2009). Elimination of OP, t-NP, 4-NP and BPA have been studied by several authors in conventional treatment plant (CTP) or membrane bioreactor (MBR) operational configurations (Clara et al., 2005; González et al., 2007). The removal ratios obtained in the MBR showed better results than the ones reported for the CTP.

Besides, the microalgae culture can be used as removal system of EDCs. The work of Nakajima et al., (2007) showed the removal of BPA by accumulation in microalgae cells after an incubation period with microalgae culture. Other authors observed the photodegradation of BPA is enhanced by algae. The algae may produce some secretions which after irradiation can produce hydroxyl radicals that can enhance the BPA degradation (Peng et al., 2006). The OP and t-NP removal can be improved by the cyanobacteria cells, this effect was enhanced at low concentrations of OP and t-NP (Stoichev et al., 2010). Whereas, the works developed by Corvini et al., (2006) proposed a mechanism for degradation of nonylphenols with bacterial strain Sphingomonas sp. which initial step of degradation is an ipso-substitution.

The aim of this research was to study the removal and fate that OP, t-NP, 4-NP and BPA experience in the presence of light, oxygen and microalgae. The experimental study was designed as a postreatment stage of a Submerged Anaerobic Membrane BioReactor (SAnMBR) located in the Cuenca del Carraixet WWTP in Alboraya (Valencia, Spain). Degradation experiments combining the studied variables were carried out in batch reactors. In order to observe the fate of EDCs in the system, a mass balance was performed considering both the soluble and the suspended fraction. 


\subsection{Fractional factorial design and set up reactors}

In order to study the effect of light $(\mathrm{P})$, oxygen $(\mathrm{O})$ and microalgae $(\mathrm{M})$ on the removal of micropollutants, a factorial experimental design was developed (Box and Hunter 1961). A full $2^{k}$ factorial design requires all combinations of two versions ( $n$ ) of each variable (f). The total number of experiments carried out was $8\left(n^{f}\right)$, which corresponds to three variables (light, oxygen and microalgae) and two version for each variable. The eight described experiments were reduced to five experiments (see Table 1). The removed experiments were those having the variable microalgae without variable light, because microalgae growth is inhibited under those conditions.

The experiments were carried out in batch mode, and the experimental setup was shown in supplementary Fig. S1, which consists of four Pyrex ${ }^{\circledR}$ reactors of $2.0 \mathrm{~L}$ of total volume, with a working volume of $1.6 \mathrm{~L}$. The reactors were kept under agitated conditions in a Walk-in Ineltec climatic chamber (Tona, Barcelona, Spain), at $20 \pm 1$ ㅇ. The reactors were fed with $800 \mathrm{~mL}$ of a SAnMBR pilot plant effluent. The remaining $800 \mathrm{~mL}$ were filled with raw microalgae culture for "POM" (light, oxygen and microalgae) experiment and $800 \mathrm{~mL}$ of pure water for "PO" (light and oxygen), "P" (light) and "O" (oxygen) experiments.

The developed experiments under forced aeration were carried out with a compress air stream (3 bar) (Atlas Copco, ZT-37-FF, Stockholm, Sweden). The compress air was connected to a diffuser at the bottom of the reactors, so the bubbles kept the

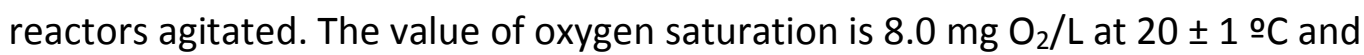
101.325 kPa (Lide, 2012). The dissolved oxygen was measured by OxiCal-SL CellOx 325 probe (WTW, Weilheim, Germany), connected to the Multi 340i meter (WTW, Weilheim, Germany). In order to maintain the $\mathrm{pH}$ between 7.2 and 7.5 in the microalgae culture reactor (POM), a stream of carbon dioxide was used. The $\mathrm{pH}$ was measured by WTW SenTix 41 probe (WTW, Weilheim, Germany), connected to Consort pH Meter model C861 (Turnhout, Belgium). Besides, the carbon dioxide stream provides a source of inorganic carbon needed for microalgae growth. Both gases, oxygen and carbon dioxide, were connected to the same diffuser.

The experiments under illuminated conditions were irradiated by four fluorescent lamps (Sylvania Grolux, United Kingdom, London) of $18 \mathrm{~W}$ of nominal wattage (590 mm width, $26 \mathrm{~mm}$ E.D.) which achieve a constant irradiation. The Grolux lamp spectrum produces high concentration of photosynthetically active radiation (PAR). PAR was measured in the illuminated surface of reactors, resulting in a value of $120 \mu \mathrm{E} / \mathrm{m}^{2} \cdot \mathrm{s}$. HOBO Photosynthetic Light Smart Sensor and HOBO Micro Station Data 
Logger (MicroDAQ.com Ltd, Contoocook, NH, USA) were used in order to measure the PAR.

The experiments under dark conditions were carried out with the reactors wrapped with foil and the fluorescents lamps turned off.

Every reactor was spiked with 5.6, 24.0, 16.0 and $16.0 \mu \mathrm{g}$ of OP, t NP, 4-NP and $B P A$ respectively. The chosen fortification corresponds to 5 times the average concentration of the SAnMBR effluent pilot plant for each micropollutant (Abargues et al., 2012).

The SAnMBR effluent used in the experiments comes from an anaerobic bioreactor pilot plant of $1.3 \mathrm{~m}^{3}$ total volume $\left(0.4 \mathrm{~m}^{3}\right.$ head-space volume) connected to two membrane tanks of $0.8 \mathrm{~m}^{3}$ total volume each $\left(0.2 \mathrm{~m}^{3}\right.$ head-space volume) which treats urban wastewater (Giménez et al., 2011). Each membrane tank includes one industrial hollow-fibre ultrafiltration membrane module (PURON ${ }^{\circledR}$ Koch Membrane Systems (PUR-PSH31), $0.05 \mu \mathrm{m}$ pore size). The SAnMBR pilot plant was located in the Cuenca del Carraixet WWTP in Alboraya (Valencia, Spain).

The average wastewater characteristics of the SAnMBR effluent during the studied period were: $309 \pm 3 \mathrm{mg} \mathrm{COD} / \mathrm{L}, 54 \pm 14 \mathrm{mg} \mathrm{BOD} / \mathrm{L}, 54 \pm 6 \mathrm{mg} \mathrm{NH}_{4}{ }^{+}-\mathrm{N} / \mathrm{L}, 8.5 \pm$ $1.1 \mathrm{mg} \mathrm{PO}_{4}{ }^{3-}-\mathrm{P} / \mathrm{L}, 70 \pm 30 \mathrm{mg} \mathrm{SO}_{4}{ }^{2-}-\mathrm{S} / \mathrm{L}, 128 \pm 2 \mathrm{mg} \mathrm{s}^{2-} / \mathrm{L}, 12 \pm 3 \mathrm{mg} \mathrm{COD} / \mathrm{L}$ of Volatile Fatty Acids and $610 \pm 110 \mathrm{mg} \mathrm{CaCO} / \mathrm{L}$ of Alkalinity. Solids, COD, BOD, sulphate, sulphide, and nutrients were determined according to Standard Methods (APHA, 2005). The carbonate alkalinity and volatile fatty acids concentration were determined by titration according to the method proposed by WRC (1992).

\subsection{Reagents, solutions and microalgae culture}

All the reagents were of analytical grade. 4-n-nonylphenol (4-NP) (CAS Number 104-40-5) and technical nonylphenol (t-NP) (CAS Number 84852-15-3) were obtained from Riedel-de Haën (Seelze, Germany). 4-(1,1,3,3-tetramethylbutyl)phenol (OP) (CAS Number 140-66-9) and bisphenol-A (BPA) (CAS Number 80-05-7) were purchased from Sigma-Aldrich (Steinheim, Germany).

Ethanol was purchased from Panreac (Barcelona, Spain) and acetonitrile was purchased from Sigma-Aldrich (Steinheim, Germ any). The pure water was obtained by means of a Synergy UV purification system purchased from Milli-Q (Millipore, Billerica, MA, USA). Helium, nitrogen and carbon dioxide were purchased from Carburos Metálicos (Barcelona, Spain).

The stock solutions of standards were prepared in ethanol up to a maximum concentration of $1000 \mathrm{mg} / \mathrm{L}$. The more dilute solutions were prepared from stock 
solutions directly in pure water up to a maximum concentration of $1 \mathrm{mg} / \mathrm{L}$. All solutions were kept at 4 으 until use.

The microalgae used as inoculum were obtained from the walls of the secondary clarifier of the Carraixet WWTP and kept in the laboratory under semicontinuous feeding of SAnMBR effluent and with continuous illumination varying between 114 and $198 \mu \mathrm{E} \cdot \mathrm{m}^{-2} \cdot \mathrm{s}^{-1}$. Microalgae from the chlorococcales order of the Chlorophyceae class and cyanobacteria were identified as the main groups present in the inoculum (Ruiz-Martinez et al., 2012). The pH of the medium was adjusted to 7.2-7.5 by using $\mathrm{CO}_{2}$.

\subsection{Analytical Methods}

Solid phase microextraction (SPME), as pre-concentration technique, was used for the determination of the interest analytes (Guillot et al., 2006; Tan et al., 2008). The pre-concentrated was analysed by gas chromatography coupled to mass spectrometry detector (GC-MS).

In order to know the fate and removal of micropollutants both soluble and suspended fractions were analysed. The final result was obtained by averaging the $n$ (3) repetitions performed for both fractions. The analyses were performed at room temperature.

\subsubsection{Soluble Fraction Analysis}

The SPME procedure was carried out with $20 \mathrm{~mL}$ of sample, which were placed in a $20 \mathrm{~mL}$ clear vial screw top (Supelco, Bellefonte, PA, USA) with a magnetic stir bar (VWR International Eurolab, Barcelona, Spain). Polyacrylate fibre (Supelco, Bellefonte, $\mathrm{PA}$, USA) was immersed inside the sample with constant stirring (1500 rpm) during 60 $\mathrm{min}$. The fibre was immediately removed and placed in the injection port of the GC-MS for micropollutants desorption during $15 \mathrm{~s}$. The described method was adapted from a previous work (Moliner-Martinez et al., 2013).

\subsubsection{Suspended Fraction Analysis}

The POM reactor samples were centrifuged at $5000 \mathrm{rcf}$ for 5 minutes (Eppendorf centrifuge 5804 R, Brinkmann Instruments, Westbury, NY, USA). The supernatant was discarded, whereas suspended fraction was dehydrated by freeze-dried. $0.10 \pm 0.01 \mathrm{~g}$ of the dehydrated sample was accurately weighted and placed in a $20 \mathrm{~mL}$ clear vial screw top with $2.5 \mathrm{~mL}$ of ACN. The standards and samples were weighed with a Mettler-Toledo microbalance XP105 Delta Range (Greifensee, Switzerland) with a resolution of $0.01 \mathrm{mg}$. The samples were sonicated in an ultrasonic bath for 60 min at 65 ㄷ ( $150 \mathrm{~W}, 40 \mathrm{kHz}$, JP Selecta, Barcelona, Spain), and then were centrifuged at $5000 \mathrm{rcf}$ for 5 minutes. $2.0 \mathrm{~mL}$ of supernatant were placed in a $20 \mathrm{~mL}$ 
clear vial screw top with a magnetic stir bar (7 mm E.D., $20 \mathrm{~mm}$ width) and $18.0 \mathrm{~mL}$ of water were added. After that, the soluble fraction was pre-concentrated with the SPME-GC-MS technique describe above.

\subsection{Chromatographic conditions}

The whole analyses were performed on a gas chromatography-mass spectrometry system (GC-MS) using 6890N GC with 5973 inert MS Detector (Agilent, Palo Alto, CA, USA) equipped with a split/splitless injection port and operated by MSD Chemstation Software (Agilent, Palo Alto, CA, USA). The capillary column is a fusedsilica HP-5ms Ultra Inert (30.0 m, $250 \mu \mathrm{m}$ I.D., $0.25 \mu \mathrm{m}$ film thickness) (Agilent, Palo Alto, CA, USA).

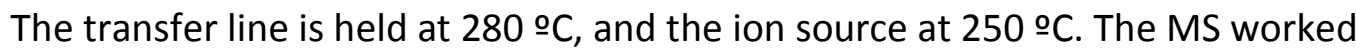
in selected-ion-monitoring (SIM) mode and the electron impact energy is set to 69.9 $\mathrm{eV}$. The GC-MS was operated in splitless mode and the injection port temperature was held isothermally at 280 ㄷ. The temperature program used was as follows: initial temperature of $50 \stackrel{\circ}{\circ}$, $30{ }^{\circ} \mathrm{C} / \mathrm{min}$ to $140{ }^{\circ} \mathrm{C}$, held for $1 \mathrm{~min}, 20{ }^{\circ} \mathrm{C} / \mathrm{min}$ to $280 \stackrel{\circ}{\circ}$, held

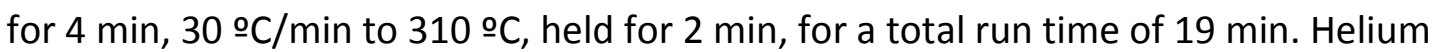
was used as carrier gas with a flow of $1.0 \mathrm{~mL} / \mathrm{min}$.

\subsection{Analytical parameters}

In order to find the characteristic ions and the relative abundance of each compound the GC-MS system was carried out in full scan mode (scan range from 100 to $300 \mathrm{~m} / \mathrm{z}$ ).

The selected ion monitoring (SIM) mode analysis was used to determine the quality assurance parameters such as detection and quantification limits, precision and linearity. The analytical procedure was validated in terms of linear dynamic range and intra-day precision (Relative Standard Deviation, RSD).

The limit of detection (LOD) and limit of quantification (LOQ) were determined experimentally as the lowest concentration giving a chromatographic peak three times the signal/noise ratio and ten times the signal/noise ratio, respectively.

\subsubsection{Soluble fraction}

Table 2 shows LOD, RSD, calibration line parameters, correlation coefficient and lineal range for the analysis of the soluble fraction. The LOD values ranged from 2 to $500 \mathrm{ng} / \mathrm{L}$.

The determined regression coefficients were always higher than 0.99, except for 4-NP whose coefficient was 0.98 . The precision for the methods was evaluated by 
the statistical parameter RSD. The RSD values of the soluble fraction were obtained by spiking aqueous samples with 1.0, 5.0, 10.0 and $50.0 \mu \mathrm{g} / \mathrm{L}$ for OP, 4-NP, t-NP and BPA respectively of nominal concentrations. Satisfactory values equal or lower than $20 \%$ were obtained in all cases.

\subsubsection{Suspended fraction}

Table 3 shows LOD, RSD, calibration line parameters, correlation coefficient and lineal range for the analysis of the suspended fraction. The LOD values ranged from 10 to $1000 \mathrm{ng} / \mathrm{kg}$. The determined regression coefficients were ranged from 0.96 to 0.98 , except for BPA, whose regression coefficient was 0.90 .

The RSD values of the suspended fraction were obtained by spiking the solid sample with 0.4, 2.0, 4.0 and $20.0 \mu \mathrm{g} / \mathrm{kg}$ for OP, 4-NP, t-NP and BPA respectively. Spiked solid samples were immediately sonicated and analysed. The obtained results were lower than $18 \%$ in all cases.

\section{Results and discussion}

3.1. Degradation of micropollutants without microalgae, oxygen and light

In order to check the spontaneous degradation of micropollutants, an experiment without the variables light, oxygen and microalgae was carried out. The observed relative concentration $\left(C / C_{0}\right)$ was calculated as the concentration at specific time divided by the initial concentration of each micropollutant. The $\mathrm{C} / \mathrm{C}_{0}$ was kept between $90 \%$ and $102 \%$ showing that the natural degradation of micropollutants was not significant, due to the RSD of the method was between 13 and $20 \%$.

\subsection{Effect of light, oxygen and microalgae on micropollutants removal}

The average characteristics of the microalgae culture reactor (POM) during the experiment were $500 \pm 200 \mathrm{mg}$ TSS/L, $24 \pm 10 \mathrm{mg} \mathrm{NH}_{4}{ }^{+}-\mathrm{N} / \mathrm{L}, 0.27 \pm 0.07 \mathrm{mg} \mathrm{NO}_{2}{ }^{-} \mathrm{N} / \mathrm{L}$, $1.1 \pm 0.4 \mathrm{mg} \mathrm{NO}_{3}{ }^{-} \mathrm{-N} / \mathrm{L}$ and $1.4 \pm 1.3 \mathrm{mg} \mathrm{PO}_{4}{ }^{3-}-\mathrm{P} / \mathrm{L}$. The average values of dissolved oxygen were $8.2 \pm 0.5,8.1 \pm 0.3$ and $8.2 \pm 0.4 \mathrm{mg} \mathrm{O}_{2} / \mathrm{L}$ for "POM", "PO" and "O" experiments respectively. In order to remove the dissolved oxygen (DO) concentration in the experiment " $P$ ", the reactor was bubbled with nitrogen during $30 \mathrm{~min}$, reducing the concentration value of $\mathrm{DO}$ to $1.8 \pm 0.9 \mathrm{mg} \mathrm{O} / \mathrm{L}$. Figure 1 shows the evolution of the micropollutants soluble concentrations during the experiments.

The results obtained for OP and t-NP, in the soluble fraction, showed that in "POM", "PO" and "O" experiments the micropollutants were removed faster than in the " $P$ ", experiment, achieving removal ratios above $95 \%$ after $22.5 \mathrm{~h}$ (the first quarter of experiment) for aerated experiments. The removal ratios in the " $\mathrm{P}$ " experiment were close to $50 \%$ for both micropollutants. The removal ratios after $90 \mathrm{~h}$ were higher 
than $96 \%$ for "POM", "PO" and " $\mathrm{O}$ " experiments while for " $\mathrm{P}$ " experiment the removal ratios were lower than $66 \%$ for OP and t-NP.

For 4-NP the four experiments achieved similar removal rates that the ones achieved for OP and t-NP. The removal ratios were higher than $90 \%$ after $22.5 \mathrm{~h}$ for the "POM", "PO" and "O" experiments and close to $75 \%$ for the " $P$ " experiment. After $90 \mathrm{~h}$, the removal ratios were $100 \%$ in all experiments. This behaviour can be explained due to 4-NP is easier to degrade, because this micropollutant could undergo the ipso-substitution mechanism described in literature (Corvini et al., 2006; Porter et al., 2012).

The removal results obtained for BPA showed that aerated experiments produced faster removal than the non-aerated experiment. The obtained removal ratios in aerated experiments were between 91.9 and $99.8 \%$ after the first $22.5 \mathrm{~h}$. Whereas, the non-aerated experiment showed removal ratios close to $80 \%$. The removal ratios after $90 \mathrm{~h}$ were higher than $96 \%$ for "POM", "PO" and "O". However the removal ratio for " $P$ " experiment was only $79.8 \%$. This value is significantly lower than the values obtained in the aerated experiments.

In general the removal observed after $90 \mathrm{~h}$ in the " $\mathrm{P}$ " experiment was less effective than in the other three experiments, except for 4-NP. The main difference among the experiments was the lower DO concentration in the " $\mathrm{P}$ " experiment. The DO value for " $P$ " experiment was $1.8 \pm 1.0 \mathrm{mg} \mathrm{O} / \mathrm{L}$, whereas for "POM", "PO" and "O" experiments was $8.2 \pm 0.8 \mathrm{mg} \mathrm{O}_{2} / \mathrm{L}$. This observation is in accordance with literature which suggests that the oxygen is necessary for attacking the aromatic rings (Lika and Papadakis, 2009).

\subsection{Mass Balance}

The mass balance was calculated once the experiments were finished ( $90 \mathrm{~h}$ ). The suspended fraction, in "POM" experiment, was separated from supernatant by centrifugation and analysed.

Two methods for carrying out the mass balance are described in the literature (Carballa et al., 2007; Estrada-Arriaga and Mijaylova, 2011). The first method uses measured data for soluble and suspended fractions, whereas the second method uses the solid-water distribution coefficients to calculate the concentrations in the sludge from those measured in the soluble phase. The method based on measure data was used in this work. The mass of each micropollutant in influent $\left(M_{1}\right)$ and effluent $\left(M_{E}\right)$ were determined according to the equations (1) and (2). The removal in the system was studied separating the two processes: sorption $\left(M_{S}\right)$ and degradation $\left(M_{D}\right)$, defined in Equations (3) and (4) respectively. The removal ratios by sorption processes 
$319\left(R_{S}\right)$ and by degradation processes $\left(R_{D}\right)$ were evaluated with the equations $(5)$ and $(6)$ 320 respectively.

$$
\mathrm{M}_{1}=\mathrm{V} \cdot \mathrm{S}_{\mathrm{I}}
$$

$$
M_{E}=V \cdot\left(S_{E}+T S S \cdot X\right)
$$

$$
\mathrm{M}_{\mathrm{S}}=\mathrm{V} \cdot \mathrm{TSS} \cdot \mathrm{X}
$$$$
M_{D}=M_{1}-M_{E}-M_{S}
$$$$
R_{S}=100-\left(\left(M_{S} / M_{l}\right) \cdot 100\right)
$$$$
R_{D}=100-\left(\left(M_{D} / M_{1}\right) \cdot 100\right)
$$

where $M$ is the mass of EDCs $(\mu \mathrm{g}), V$ is the volume treated in batch system $(\mathrm{L}), \mathrm{S}$ is the micropollutant concentrations in the soluble fraction $(\mu \mathrm{g} / \mathrm{L}), \mathrm{X}$ is the micropollutant concentrations in the suspended fraction $(\mu \mathrm{g} / \mathrm{kg})$ and TSS is the total suspended solids concentration each mass flux of "POM" reactor $(\mathrm{kg} / \mathrm{L})$. The influent is the permeate of SAnMBR system, thus the concentration of TSS in influent is zero.

Table 4 shows the mass fluxes of micropollutants and the removal ratios based on sorption and degradation processes in the soluble and suspended fractions for "POM" experiment and for the soluble fraction for the other experiments. Low values of $R_{S}$ were observed in "POM" experiments indicating that accumulation in the microalgae was insignificant. The $R_{S}$ values ranged from 0.06 to $4.17 \%$ respect to the initial spiked concentration. This observation was in accordance with Nakajima et al., (2007). On the other hand, the removal of the soluble fraction was higher, being the values of $R_{D}$ higher than $90 \%$ for all the micropollutants studied.

Comparing all the experimental conditions, high total removal ratios $\left(R_{S}+R_{D}\right)$ were achieved for t-NP. Values higher than $98 \%$ were observed for aerated experiments, whereas for " $P$ " experiment the total removal ratio was $65 \%$. The $R_{D}$ for OP was higher than $98 \%$ for aerated experiments, whereas it was closer to $50 \%$ for "P" experiment. Although the branched chemical structure of OP and t-NP make them resistant to degradation, the aerated conditions produced removal ratios higher than $98 \%$. The total removal ratios observed for 4-NP were higher than $99.9 \%$ in all experiments, which evidenced that this micropollutant is highly degradable. This observation was in accordance with literature (Corvini et al., 2006; Porter et al., 2012). The BPA shows the lowest $R_{D}$ for aerated experiments, which was kept between 91 and $99 \%$. Whereas under non-aerated conditions BPA the removal ratio was close to $80 \%$. The OP shows the lowest removal ratio under non-aerated conditions, thus OP seems to be the micropollutant more resistant to light. 
Comparing aerated experiments, the total removal ratios obtained for OP, t-NP and BPA were higher than $96 \%$ for " $\mathrm{PO}$ " and "O", whereas for "POM" the value ranged from 96.1 to $98.8 \%$. This could be attributed to the microalgae were able to shield the light, therefore the low removal ratio produced by photons was partly inactive.

Moreover, the micropollutants degradation under aerated conditions can be fulfilled in less than $20 \mathrm{~h}$.

\section{Conclusions}

The total removal ratios for OP, t-NP and BPA were higher under aerated conditions than under non-aerated conditions. However, it was observed a complete removal for 4-NP in all experiments. The chemical oxidation is the key variable in the micropollutants removal and photodegradation was only effective on 4-NP. The removal by sorption was much lower than by degradation. Therefore an aerobic step should be required to remove the studied compounds from the SAnMBR effluent. Further studies must be performed in order to optimise the DO concentration. Moreover, the photosynthetic activity of microalgae in terms of DO supplier should be assessed.

\section{Acknowledgement}

This research work has been supported by the Spanish Ministry of Economy and Competitiveness (MINECO, Projects CTM2011-28595-C02-01/02) jointly with the European Regional Development Fund (ERDF), The Government of the Region of Valencia (Generalitat Valenciana), within the research project "Application of Water Framework Directive 2000/60/EC on endocrine disruptors and priority substances in coastal areas in the Comunitat Valenciana" and by the Spanish Research Foundation (MINECO, project CTM2008-060809-C02-01/TECNO), within the research project "Feasibility of the SAnMBR technology to treat urban wastewater, and the technical and economic feasibility to industrial implementation" which are gratefully acknowledged. 


\section{References.}

1. Abargues, M.R., Robles, A., Bouzas, A., Seco, A. 2012. Micropollutants removal in an anaerobic membrane bioreactor and in an aerobic conventional treatment plant. Water Sci. Technol. 65.12, 2242-2250.

2. Allan, I.J., Vrana, B., Greenwood, R., Mills, G.A., Roig, B., Gonzalez, C. 2006. A "toolbox" for biological and chemical monitoring requirements for the European Union's Water Framework Directive. Talanta 69, 302-322.

3. APHA, 2005. Standard Methods for the Examination of Water and Wastewater, $21^{\text {st }}$ ed. American Public Health Association/American Water Works Association/Water Environmental Federation, Washington (DC), USA.

4. Box, G.E.P., Hunter, J.S. 1961. The $2^{k-p}$ Fractional Factorial Designs Part I. Technometrics 3, 311-351.

5. Carballa, M., Omil, F., Lema, J.M. 2007. Calculation Methods to Perform Mass Balances of Micropollutants in Sewage Treatment Plants. Application to Pharmaceutical and Personal Care Products (PPCPs). Environ. Sci. Technol. 41, 884-890.

6. Careri, M., Elviri, L., Mangia, A., Zagnoni, I. 2003. Liquid ChromatographyElectrospray Ionization Tandem Mass Spectrometry and Liquid Chromatography with Fluorescence Detection for Determination of Octylphenol and Nonylphenol in Municipal Wastewater at Trace Levels. Chromatographia 57, 321-327.

7. Clara, M., Strenn, B., Gans, O., Martinez, E., Kreuzinger, N., Kroiss, H. 2005. Removal of selected pharmaceuticals, fragrances and endocrine disrupting compounds in a membrane bioreactor and conventional wastewater treatment plants. Water Research 39, 4797-4807.

8. Corvini, P.F.X., Hollender, J., Ji, R., Schumacher, S., Prell, J., Hommes, G., Priefer, U., Vinken, R., Schäffer, A. 2006. The degradation of $\alpha$-quaternary nonylphenol isomers by Sphingomonas sp. strain TTNP3 involves a type II ipso-substitution mechanism. Appl. Microbiol. Biotechnol. 70, 114-122.

9. de Weert, J., Viñas, M., Grotenhuis, T., Rijnaarts, H., Langenhoff, A. 2010. Aerobic nonylphenol degradation and nitro-nonylphenol formation by microbial cultures from sediments. Appl. Microbiol. Biotechnol. 86, 761-771.

10. Estrada-Arriaga, E.B., Mijaylova, P. 2011. Calculation methods to perform mass balance of endocrine disrupting compounds in a submerged membrane 
bioreactor: fate and distribution of estrogens during the biological treatment. Water Sci. Technol. 64, 2158-2168.

11. European Commission, 2000. Directive 2000/60/EC of the European Parliament and of the Council of 23 October 2000 establishing a framework for Community action in the field of water policy. Official Journal of the European Union L327, 177.

12. European Commission, 2008. European Parliament and Council, Directive 2008/105/EC of the European Parliament and of the Council of 16 December 2008 on environmental quality standards in the field of water policy, amending and subsequently repealing Council Directives 82/176/EEC, 83/513/EC, 84/156/EEC, 84/491/EEC, 86/280/EEC and amending Directive 2000/60/EC of the European Parliament and of the Council. Official Journal of the European Union L348, 84-97.

13. European Commission, 2011. Proposal for a Directive 2011/0429 (COD) of the European Parliament and of the Council, amending Directives 2000/60/EC and $2008 / 105 / E C$ as regards priority substances in the field of water policy.

14. Gattullo, C.E., Bährs, H., Steinberg, C.E.W., Loffredo, E. 2012. Removal of bisphenol A by the freshwater green alga Monoraphidium braunii and the role of natural organic matter. Science of the Total Environment 416, 501-506.

15. Giménez, J.B., Robles, A., Carretero, L., Durán, F., Ruano, M.V., Gatti, M.N., Ribes, J., Ferrer, J., Seco., A. 2011. Experimental study of the anaerobic urban wastewater treatment in a submerged hollow-fibre membrane bioreactor at pilot scale. Bioresour. Technol. 102, 8799-8806.

16. González, S., Petrovic, M., Barceló, D. 2007. Removal of a broad range of surfactants from municipal wastewater - Comparison between membrane bioreactor and conventional activated sludge treatment. Chemosphere 67, 335343.

17. Guillot, S., Kelly, M.T., Fenet, H., Larroque, M. 2006. Evaluation of solid-phase microextraction as an alternative to the official method for the analysis of organic micro-pollutants in drinking water. Journal of Chromatography A 1101, 46-52.

18. Ike, M., Chen, M.Y., Danzl, E., Sei, K., Fujita, M. 2006. Biodegradation of a variety of bisphenols under aerobic and anaerobic conditions. Water Sci. Technol. 53 153-9. 
19. Janex-Habibi, M.L., Huyard, A., Esperanza, M., Bruchet, A. 2009. Reduction of endocrine disruptor emissions in the environment: The benefit of wastewater treatment. Water Research 43, 1565-1576.

20. Jobling, S., Sumpter, J.P. 1993. Detergent components in sewage effluent are weakly oestrogenic to fish: An in vitro study using rainbow trout (Oncorhynchus mykiss) hepatocytes. Aquatic Toxicology 27, 361-372.

21. Kang, J.H., Kondo, F. 2002. Bisphenol A Degradation by Bacteria Isolated from River Water. Arch. Environ. Contam. Toxicol. 43, 265-269.

22. Manente, L., Sellitti, A., Lucariello, A., Laforgia, V., De Falco, M., De Luca, A. 2011. Effects of 4-nonylphenol on proliferation of AGS gastric cells. Cell Prolif. 44, 477-485.

23. Moliner-Martinez, Y., Pastor-Carbonell, J.M., Bouzas, A., Seco, A., Abargues, M.R., Campins-Falco P. 2013. Guidelines for alkylphenols estimation as alkylphenol polyethoxylates pollution indicator in wastewater treatment plant effluents. Anal. Methods 5, 2209-2217.

24. Nakajima, N., Teramoto, T., Kasai, F., Sano, T., Tamaoki, M., Aono, M., Kubo, A., Kamada, H., Azumi, Y., Saji, H. 2007. Glycosylation of bisphenol A by freshwater microalgae. Chemosphere 69, 934-941.

25. Lide, D.R. 2012. CRC Handbook of Chemistry and Physics $92^{\text {nd }}$ Edition Internet Version.

26. Lika, K., Papadakis, I.A. 2009. Modeling the biodegradation of phenolic compounds by microalgae. Journal of Sea Research 62, 135-146.

27. Lin, Y.W., Guo, G.L., Hsieh, H.C., Huang, S.L. 2010. Growth of Pseudomonas sp. TX1 on a wide range of octylphenol polyethoxylate concentrations and the formation of dicarboxylated metabolites. Bioresour. Technol. 101, 2853-2859.

28. Peng, Z., Wu, F., Deng, N. 2006. Photodegradation of bisphenol A in simulated lake water containing algae, humic acid and ferric ions. Environmental Pollution $144,840-846$.

29. Porter, A.W., Campbell, B.R, Kolvenbach, B.A., Corvini, P.F.X., Benndorf, D., Rivera-Cancel, G., Hay A.G. (2012). Identification of the flavin monooxygenase responsible for ipso substitution of alkyl and alkoxyphenols in Sphingomonas sp. TTNP 3 and Sphingobium xenophagum Bayram. Appl. Microbiol. Biotechnol. 94, 261-272. 
3

30. Ruiz-Martinez, A., Martin Garcia, M., Romero, I., Seco, A., Ferrer, J. (2012). Microalgae cultivation in wastewater: Nutrient removal from anaerobic membrane bioreactor effluent. Bioresour. Technol. 126, 247-253.

31. Sharma, V.K., Anquandah, G.A.K., Yngard, R.A., Kim H., Fekete J., Bouzek, K., Ray A.K., Golovko, D. 2009. Nonylphenol, octylphenol, and bisphenol-A in the aquatic environment: A review on occurrence, fate, and treatment. Journal of Environmental Science and Health Part A 44, 423-442.

32. Stoichev, T., Basto, M.C.P., Vasconcelos, V., Vasconcelos, M.T.S.D. 2010. Fate and effects of nonylphenol in the presence of the cyanobacterium Microcystis aeruginosa. Chemistry and Ecology 26, 395-399.

33. Tabira, Y., Nakai, M., Asai, D., Yakabe, Y., Tahara, Y., Shinmyozu, T., Noguchi, M., Takatsuki, M., Shimohigashi, Y. 1999. Structural requirements of paraalkylphenols to bind to estrogen receptor. Eur. J. Biochem. 262, 240-245.

34. Tan, B.L.L., Hawker, D.W., Müller, J.F., Tremblay, L.A., Chapman, H.F. 2008. Stir bar sorptive extraction and trace analysis of selected endocrine disruptors in water, biosolids and sludge samples by thermal desorption with gas chromatography-mass spectrometry. Water Research 42, 404-412.

35. WRC, 1992. Simple titration procedures to determine $\mathrm{H}_{2} \mathrm{CO}_{3}$ /alkalinity and short-chain fatty acids in aqueous solutions containing known concentrations of ammonium, phosphate and sulphide weak acid/bases, Report No. TT 57/92. Water Research Commission, University of Cape Town, Pretoria, Republic of South Africa.

(1) 


\section{Figure captions.}

Figure 1. Effect of light, oxygen and microalgae combination; "POM" (light, oxygen and microalgae), "PO" (light and oxygen), " $\mathrm{P}$ " (light) and "O" (oxygen) on the micropollutants in soluble concentrations. Removal is shown through of the variation of relative micropollutants concentration with time. The initial concentrations were 3.5, 15.0, 10.0 and $10.0 \mathrm{\mu g} / \mathrm{L}$ for OP, t-NP, 4NP and BPA respectively. The average exposure total time was $90 \mathrm{~h}$ for each experiment

516 

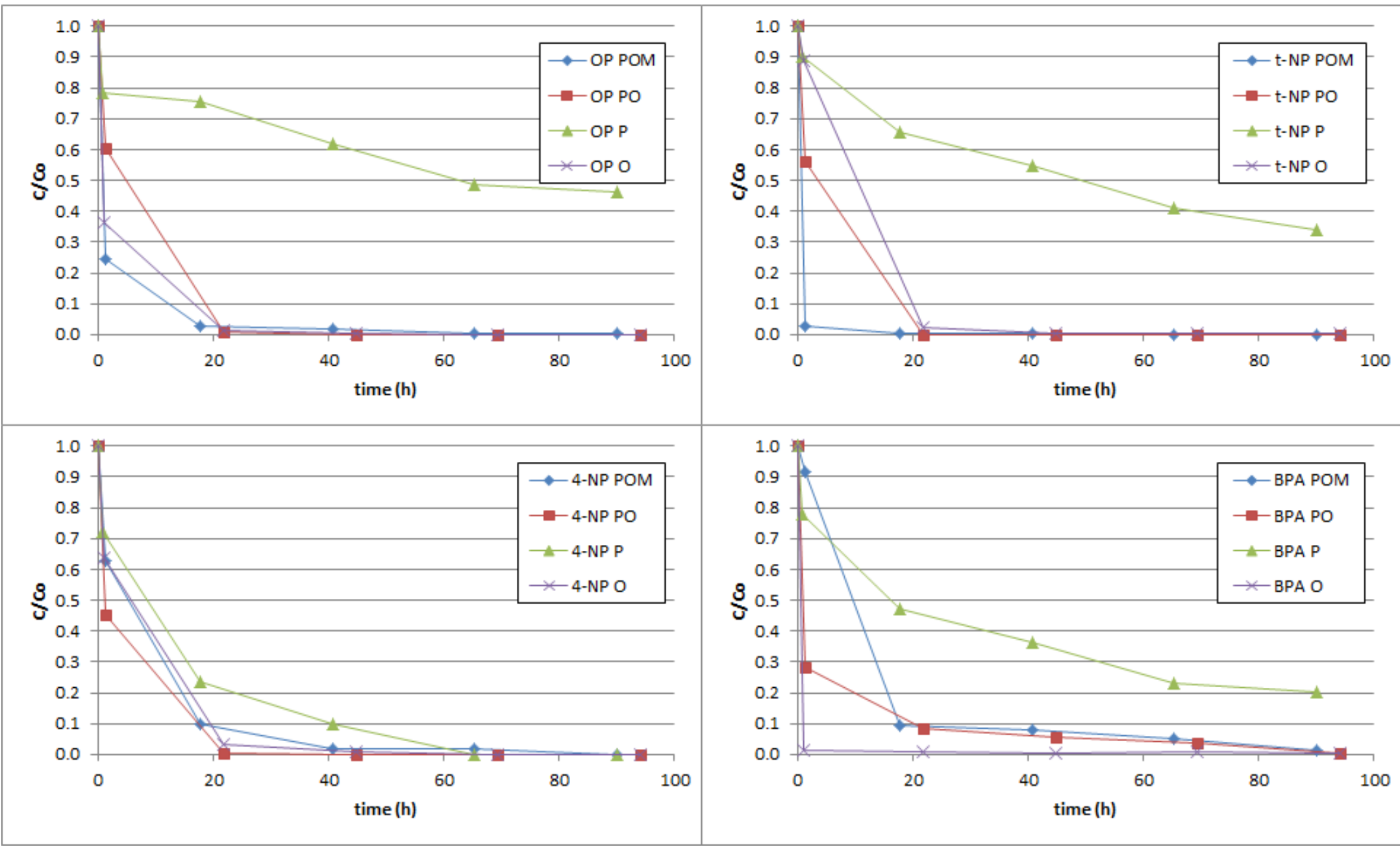

$519 \quad$ Fig. 1 


\begin{tabular}{cccccccc}
\cline { 2 - 7 } & \multicolumn{3}{c}{ Value of variables } & \multicolumn{4}{c}{ Code } \\
\hline $\begin{array}{c}\text { Treatment } \\
\text { combination }\end{array}$ & $\mathbf{O}\left(\mathrm{mg} \mathrm{O}_{\mathbf{2}} / \mathrm{L}\right)$ & $\mathbf{P}\left(\mu \mathrm{E} / \mathrm{m}^{2} \cdot \mathbf{s}\right)$ & $\mathbf{M}($ cells $/ \mathrm{L})$ & $\mathbf{O}$ & $\mathbf{P}$ & $\mathbf{M}$ \\
\hline POM & $8.2 \pm 0.5$ & 120 & $2,25 \cdot 10^{10}$ & + & + & + \\
PO & $8.1 \pm 0.3$ & 120 & 0 & + & + & - \\
$\mathbf{P}$ & $1.8 \pm 0.9$ & 120 & 0 & - & + & - \\
$\mathbf{O}$ & $8.2 \pm 0.4$ & 0 & 0 & + & - & - \\
$\mathbf{1}$ & $1.8 \pm 0.9$ & 0 & 0 & - & - & - \\
\hline
\end{tabular}

523

524 Table 1. A typical factorial design established for three variables; oxygen (O), light $(P)$ and microalgae $(M)$ at two levels.

526 


\begin{tabular}{cccccccc}
\hline EDC & LOD $(\mathrm{ng} / \mathrm{L})$ & $\mathrm{LOQ}(\mathrm{ng} / \mathrm{L})$ & $\mathrm{a} \pm \mathrm{s}_{\mathrm{a}}$ & $\mathrm{b} \pm \mathrm{s}_{\mathrm{b}}$ & $\mathrm{r}^{2}$ & Range $(\mathrm{ng} / \mathrm{L})$ & $\mathrm{RSD}(\%)$ \\
\hline OP & 2 & 6,7 & $(-18 \pm 4) \times 10^{5}$ & $(11 \pm 5) \times 10^{3}$ & 0,990 & $2-6000$ & 18 \\
t-NP & 25 & 83,3 & $(-6 \pm 2) \times 10^{6}$ & $(5 \pm 0.2) \times 10^{3}$ & 0,990 & $25-50000$ & 18 \\
4-NP & 8 & 26,7 & $(-8 \pm 3) \times 10^{6}$ & $(12 \pm 0.5) \times 10^{3}$ & 0,98 & $5-10000$ & 20 \\
BPA & 500 & 1666,7 & $(-4 \pm 2) \times 10^{5}$ & $(4.4 \pm 0.2) \times 10^{2}$ & 0,990 & $500-50000$ & 16 \\
\hline
\end{tabular}

528

529

Table 2. Analytical parameters obtained for micropollutants with SPME-GC-MS

530 for soluble fraction. LOD, LOQ, calibration line parameters (where " $a$ " is yintercept and " $b$ " is slope), correlation coefficient $\left(r^{2}\right)$, linear dynamic range and intra-day precision (RSD) are shown. 


\begin{tabular}{cccccccc}
\hline EDC & LOD $(\mathrm{ng} / \mathrm{kg})$ & $\mathrm{LOQ}(\mathrm{ng} / \mathrm{kg})$ & $\mathrm{a} \pm \mathrm{s}_{\mathrm{a}}$ & $\mathrm{b} \pm \mathrm{s}_{\mathrm{b}}$ & $\mathrm{r}^{2}$ & Range $(\mathrm{ng} / \mathrm{kg})$ & $\mathrm{RSD}(\%)$ \\
\hline OP & 10 & 33,3 & $(-20 \pm 8) \times 10^{5}$ & $(14 \pm 1) \times 10^{3}$ & 0,98 & $10-10000$ & 12 \\
t-NP & 50 & 166,7 & $(-6 \pm 5) \times 10^{6}$ & $(6.4 \pm 0.5) \times 10^{3}$ & 0,96 & $100-100000$ & 7 \\
4-NP & 20 & 66,7 & $(-11 \pm 4) \times 10^{6}$ & $(16.0 \pm 0.8) \times 10^{3}$ & 0,98 & $20-20000$ & 17 \\
BPA & 1000 & 3333,3 & $(2.6 \pm 0.9) \times 10^{6}$ & $(7 \pm 1) \times 10^{3}$ & 0,90 & $1000-100000$ & 11 \\
\hline
\end{tabular}

Table 3. Analytical parameters obtained for micropollutants with SPME-GC-MS for suspended fraction. LOD, LOQ, calibration line parameters (where " $a$ " is yintercept and " $b$ " is slope), correlation coefficient $\left(r^{2}\right)$, linear dynamic range and intra-day precision (RSD) are shown. 


\begin{tabular}{|c|c|c|c|c|c|}
\hline \multirow[b]{2}{*}{ Set-up } & \multirow[b]{2}{*}{ Sample } & \multicolumn{4}{|c|}{ Mass Flux $(\mu \mathrm{g} / \mathrm{d})$} \\
\hline & & OP & $t-N P$ & 4-NP & BPA \\
\hline \multirow[t]{6}{*}{ POM } & $M_{1}$ & 0.73 & 3.13 & 2.08 & 2.08 \\
\hline & $\mathrm{M}_{\mathrm{E}}$ & 0.01 & 0.04 & 0.00 & 0.08 \\
\hline & $M_{s}$ & 0.0076 & 0.0696 & 0.0013 & 0.0869 \\
\hline & $M_{D}$ & 0.71 & 3.02 & 2.08 & 1.92 \\
\hline & $\mathrm{R}_{\mathrm{S}}(\%)$ & 1.05 & 2.23 & 0.06 & 4.17 \\
\hline & $\mathrm{R}_{\mathrm{D}}(\%)$ & 97.75 & 96.47 & 99.90 & 91.89 \\
\hline \multirow[t]{3}{*}{ PO } & $M_{1}$ & 0.73 & 3.13 & 2.08 & 2.08 \\
\hline & $\mathrm{M}_{\mathrm{E}}$ & 0.00 & 0.00 & 0.00 & 0.00 \\
\hline & $\mathrm{R}_{\mathrm{D}}(\%)$ & 99.98 & 99.98 & 100.00 & 99.82 \\
\hline \multirow[t]{3}{*}{$P$} & $\mathrm{M}_{\mathrm{I}}$ & 0.73 & 3.13 & 2.08 & 2.08 \\
\hline & $\mathrm{M}_{\mathrm{E}}$ & 0.34 & 1.06 & 0.00 & 0.42 \\
\hline & $\mathrm{R}_{\mathrm{D}}(\%)$ & 53.84 & 65.98 & 100.00 & 79.84 \\
\hline \multirow[t]{3}{*}{$\mathrm{O}$} & $\mathrm{M}_{1}$ & 0.73 & 3.13 & 2.08 & 2.08 \\
\hline & $\mathrm{M}_{\mathrm{E}}$ & 0.00 & 0.01 & 0.00 & 0.01 \\
\hline & $\mathrm{R}_{\mathrm{D}}(\%)$ & 99.93 & 99.76 & 100.00 & 99.51 \\
\hline
\end{tabular}

Table 4. Mass flux $(\mu \mathrm{g} / \mathrm{d})$, sorption removal ratio $\left(R_{s}\right)$ and biodegradation removal ratio $\left(R_{D}\right)$ of the carried out operational conditions. 